\title{
HUBUNGAN KUALITAS PELAYANAN DENGAN KEPUASAN PASIEN BPJS DI INSTALASI RAWAT JALAN RSUD LABUANG BAJI MAKASSAR
}

\section{Andi Rizky Amaliah}

Sekolah Tinggi Ilmu Kesehatan Makassar qkyrizkyamaliah@yahoo.com

\begin{abstract}
Patient satisfaction is a function of the patient's assessment of the health services provided by the hospital in the hope that before the patient receives health services from the hospital as a provider, the patient will feel satisfied if the quality of hospital services is higher or at least the same as what the patient expects. This study aims to determine the relationship between physical evidence, reliability, responsiveness, assurance and empathy with BPJS patient satisfaction.

The results showed that the quality of service physical evidence (Tangibles) $p$ (0.76)> 0.05 which means there is no relationship, reliability (reliability) $p(0.01)<0.05$ which means there is a relationship, responsiveness (responsiveness). ) $p(0.03)<0.05$, which means there is a relationship, assurance $p(0.00)<0.05$ which means there is a relationship, empathy (empathy) $p$ (1.00)> 0.05 which means no relationship.

The conclusion in this study is that there is no relationship between physical evidence service quality and empathy with patient satisfaction, and there is a significant relationship between service quality reliability, responsiveness, and assurance with BPJS patient satisfaction. It is suggested to the hospital to further improve service quality, reliability, responsiveness, and assurance in order to increase BPJS patient satisfaction.
\end{abstract}

Keywords : Service Quality, Patient Satisfaction, BPJS

\begin{abstract}
ABSTRAK
Kepuasan pasien merupakan fungsi dari penilaian pasien terhadap pelayanan kesehatan yang diberikan oleh pihak rumah sakit dengan harapan sebelum pasien menerima pelayanan kesehatan dari pihak rumah sakit sebagai provider, pasien akan merasa puas jika kualitas pelayanan rumah sakit lebih tinggi atau setidaknya sama dengan yang diharapkan pasien. Penelitian ini bertujuan untuk mengetahui hubungan antara bukti fisik, kehandalan, daya tanggap, jaminan dan empati dengan kepuasan pasien BPJS.

Metode yang digunakan pada penelitian ini analitik observasional dengan rancangan cross sectional, dengan populasi sebanyak 2.823 dan sampel sebanyak 93 responden dengan Teknik Purposive Sampling.

Hasil penelitian menunjukan bahwa kualitas pelayanan bukti fisik (Tangibles) p $(0,76)\rangle$ 0,05 yang berarti tidak ada hubungan, kehandalan (reliability) $\mathrm{p}(0,01)<0,05$ yang berarti ada hubungan, daya tanggap (responsiveness) $\mathrm{p}(0,03)<0,05$ yang berarti ada hubungan, jaminan (assurance) $\mathrm{p}(0,00)<0,05$ yang berarti ada hubungan, empati (emphaty) $\mathrm{p}(1,00)>$ 0,05 yang berarti tidak ada hubungan.

Simpulan dalam penelitian ini yaitu tidak ada hubungan antara kualitas pelayanan bukti fisik dan empati dengan kepuasan pasien, dan terdapat hubungan yang bermakna antara kualitas pelayanan kehandalan, daya tanggap, dan jaminan dengan kepuasan pasien BPJS . Disarankan kepada rumah sakit untuk lebih meningkatkan kualitas pelayanan kehandalan, daya tanggap, dan jaminan agar dapat meningkatkat kepuasan pasien BPJS.
\end{abstract}

Kata kunci : Kualitas Pelayanan, Kepuasan Pasien, BPJS. 


\section{JURNAL DELIMA HARAPAN 2021}

\section{PENDAHUluan}

Kepuasan pasien merupakan fungsi dari penilaian pasien terhadap pelayanan kesehatan yang diberikan oleh pihak rumah sakit dengan harapan sebelum pasien menerima pelayanan kesehatan dari pihak rumah sakit sebagai provider, pasien akan merasa puas jika kualitas pelayanan rumah sakit lebih tinggi atau setidaknya sama dengan yang diharapkan pasien. Menelaah masalah kualitas pelayanan terutama pelayanan kesehatan di rumah sakit tidaklah mudah karena disatu sisi mempunyai tanggung jawab sosial dengan memberikan pelayanan kesehatan secara manusiawi, tetapi disisi lain juga harus memperhatikan prinsipprinsip ekonomi menyangkut penyelenggaraan rumah sakit yang memerlukan biaya investasi, operasional dan pemeliharaan yang begitu besar (Lucito dalam Yusuf, 2017).

World Health Organization menyatakan bahwa pelayanan kesehatan yang baik memberikan pelayanan yang efektif, aman, dan berkualitas tinggi kepada mereka yang membutuhkannya dengan didukung oleh sumber daya yang memadai. Upaya pembangunan kesehatan dapat berdayaguna dan Berhasil guna bila kebutuhan sumber daya kesehatan dapat terpenuhi.Sumber daya kesehatan mencakup sumber daya tenaga, sarana dan pembiayaan (WHO, 2015).

Pelayanan kesehatan merupakan faktor penting dalam meningkatkan derajat kesehatan dan kesejahteraan setiap insan diseluruh dunia. Setiap orang mempunyai hak dalam memperoleh pelayanan kesehatan dan pemerintah bertanggung jawab atas ketersediaan segala bentuk upaya kesehatan yang bermutu, aman, efisien, dan terjangkau oleh seluruh lapisan masyarakat (Pasal 19 UU No. 36 Tahun 2009). Salah satu upaya tersebut yaitu dengan peningkatan ketersediaan dan pemerataan fasilitas pelayanan kesehatan (Bappenas dalam Sulistyo, 2016).

Salah satu indikator keberhasilan pelayanan kesehatan adalah kepuasan pasien, menurut Parasuraman (2001: 26) dalam Yusuf (2017: 2) mengemukakan bahwa konsep mutu layanan yang berkaitan dengan kepuasan pasien ditentukan oleh lima unsur yang biasa dikenal dengan istilah mutu layanan "Servqual" yaitu responsiveness, assurance, tangible, empathy dan reliability (Parasuraman dalam Yusuf, 2017)

Berdasarkan hasil penelitian yang dilakukan oleh Puji Pertiwi Ilahi (2016) tentang Hubungan Kepuasan Pasien Pengguna BPJS Terhadap Kualitas Pelayanan Kesehatan di Puskesmas Nagrak Sukabumi menyatakan bahwa ada hubungan antara kepuasan pasien dengan dimensi Reliability, Responsiveness, emphaty, Assurance, dan tidak ada hubungan kepuasan pasien dengan dimensi Tangibles (Ilahi , 2016).

Rumah Sakit Umum Daerah (RSUD) Labuang Baji adalah rumah sakit milik pemerintah Kota Makassar yang tergolong dalam rumah sakit kelas B. Rumah sakit ini mampu memberikan pelayanan kedokteran spesialis dan subspesialis terbatas. Rumah sakit ini juga menampung pelayanan rujukan dari rumah sakit kabupaten. Rumah sakit ini memiliki fasilitas yang berstandar dengan didukung oleh tenaga dokter umum dan dokter spesialis yang ahli dibidangnya serta telah melayani pasien yang memiliki asuransi kesehatan atau jaminan kesehatan nasional (RSUD Labuang Baji Makassar, 2019).

Berdasarkan Indeks Kepuasan Masyarakat RSUD Labuang Baji Makassar didapatkan data yaitu rawat jalan berjumlah 13 unit pelayanan, rawat inap 14 unit pelayanan, instalasi 2 unit pelayanan dan penunjang yaitu 5 unit pelayanan. Hasil akhir akumulasi, NRR Interval - NRR Tertimbang

(3.0548) mendapatkan nilai yang telah dikonversikan sesuai dengan metode penilaian yaitu $76.37 \%$. Maka Indeks Kepuasan Masyarakat (IKM) RSUD Labuang Baji Makassar berada pada angka yang belum dikategorikan baik.

Berdasarkan data awal yang diperoleh di Rekam Medik RSUD 


\section{JURNAL DELIMA HARAPAN 2021}

Labuang Baji terdapat jumlah kunjungan pasien BPJS di Instalasi Rawat Jalan pada tahun 2016 yaitu sebesar 47.337 pasien, pada tahun 2017 yaitu sebesar 36.501 pasien dan pada tahun 2018 yaitu sebesar 33.876 pasien. Berdasarkan data tersebut, kunjungan pasien BPJS di instalasi rawat jalan RSUD Labuang baji Makassar dalam kurun waktu 2016-2018 mengalami penurunan (RSUD Labuang Baji Makassar, 2019).

Berdasarkan pada latar belakang diatas, maka peneliti tertarik untuk meneliti bagaimana Hubungan Kualitas Pelayanan dengan Kepuasan Pasien BPJS di Instalasi Rawat Jalan RSUD Labuang Baji Makassar.

\section{METODE}

Jenis penelitian yang digunakan pada penelitian ini yaitu dengan analitik observasional dengan rancangan cross sectional yaitu rancangan penelitian dengan melakukan pengukuran atau pengamatan pada saat bersamaan atau sekali waktu, dengan menggunakan pendekatan kuantitatif bertujuan untuk mengetahui hubungan antara variabel independen (bukti fisik, kehandalan, daya tanggap, jaminan dan empati untuk pasien) dengan variabel dependen (kepuasan pasien) di Instalasi rawat jalan RSUD Labuang Baji Makassar yang dilakukan pada tanggal 23 Mei - 20 Agustus 2019. Sampel dalam penelitian ini yaitu sebanyak 93 responden, dengan menggunakan teknik purposive sampling. Pengumpulan data dikumpulkan melalui wawancara dan observasi menggunakan kuesioner. Data yang diperoleh kemudian diolah dan disajikan dalam bentuk tabel frekuensi dan disertai narasi sebagai penjelasan tabel.

\section{HASIL}

a. Karakteristik Responden

Tabel 1

Distribusi Karakteristik Pasien BPJS

Rawat Jalan di RSUD Labuang Baji Makassar Tahun 2019

\begin{tabular}{lc}
\hline \multicolumn{1}{c}{ Variabel } & n \\
\hline Umur (Tahun) & \\
$17-25$ (Remaja akhir) & 4 \\
$26-35$ (Dewasa Awal) & 17
\end{tabular}

Volum8 Nomor 1 (Maret 2021)

\begin{tabular}{lcc}
36 - 45 (Dewasa Akhir) & 45 & 48,4 \\
46 - 55 (Lansi Awal) & 24 & 25,8 \\
56 - 65 (Lansia Akhir) & 3 & 3,2 \\
\hline Jenis Kelamin & & \\
\hline Laki-laki & 31 & 33,3 \\
Perempuan & 62 & 66,7 \\
\hline Pendidikan Terakhir & & \\
\hline Tidak Sekolah & 24 & 25,8 \\
Tamat SD & 12 & 12,9 \\
Tamat SMP & 13 & 14 \\
Tamat SMA & 42 & 45,2 \\
Tamat S1 & 2 & 2,2 \\
\hline Pekerjaan & & \\
\hline IRT & 48 & 51,6 \\
Pelajar/mahasiswa & 2 & 2,2 \\
PNS & 2 & 2,2 \\
Wiraswasta & 41 & 44,1 \\
\hline Status & & \\
\hline Menikah & 83 & 89,2 \\
Belum Menikah & 10 & 10,8 \\
\hline Suku & & \\
\hline Makassar & 77 & 82,8 \\
Bugis & 16 & 17,2 \\
\hline Total & $\mathbf{9 3}$ & $\mathbf{1 0 0}$ \\
\hline Subr: Data Primer & & \\
\hline & & \\
\hline
\end{tabular}

Sumber : Data Primer

Tabel 1 menunjukan bahwa distribusi frekuensi dari total 93 responden berdasarkan karakteristik umur menurut (Depkes RI, 2009) yang tertinggi 36-45 Tahun sebanyak 45 orang $(48,4 \%)$ sedangkan terendah 56-65 Tahun sebanyak 3 orang $(3,2 \%)$. Pada karakteristik jenis kelamin menunjukkan bahwa laki-laki sebanyak 33 orang $(33,3 \%)$ dan perempuan sebanyak 62 orang (66,7\%). Pada karakteristik Pendidikan terakhir menunjukan bahwa yang tertinggi tamat SMA sebanyak 42 orang $(45,2 \%)$ sedangkan terendah tamat S1 2 orang $(2,2 \%)$. Pekerjaan menunjukan bahwa yang yang tertinggi IRT sebanyak 48 orang $(51,6 \%)$ sedangkan terendah pelajar/mahasiswa sebanyak 2 orang $(2,2 \%)$ dan PNS sebanyak 2 orang $(2,2 \%)$. Pada karakteristik status menunjukkan bahwa yang sudah menikah 83 orang $(89,2 \%)$ sedangkan yang belum menikah 10 orang \% (10,8\%). Pada kategori suku menunjukkan bahwa suku makassar 77

4,3 orang $(82,8 \%)$ dan suku bugis 16 orang $18,3(17,2 \%)$. 


\section{JURNAL DELIMA HARAPAN 2021}

b. Analisis Univariat

Tabel 2

Distribusi sampel variabel di Instalasi Rawat

Jalan RSUD Labuang Baji Makassar Tahun 2019

\begin{tabular}{l}
\multicolumn{1}{c}{ Variabel } \\
\hline Bukti Fisik (Tangibles) \\
Kurang Baik \\
Baik \\
\hline Kehandalan (Reliability) \\
Kurang Baik \\
Baik \\
\hline Daya Tanggap (Responsiveness) \\
Kurang Baik \\
Baik \\
\hline Jaminan (Assurance) \\
Kurang Baik \\
Baik \\
\hline Empati (Emphaty) \\
Kurang Baik \\
Baik \\
\hline Kepuasan \\
Kurang Puas \\
Puas
\end{tabular}

Jumlah

Sumber : Data Primer

Tabel 2 menunjukan bahwa presentase sampel berdasarkan bukti fisik yang tertinggi baik sebanyak 78 orang $(83,9 \%)$ sedangkan yang terendah kurang baik sebanyak 15 orang $(16,1 \%)$, presentase sampel berdasarkan kehandalan yang tertinggi baik sebanyak 68 orang $(73,1 \%)$ sedangkan yang terendah kurang baik sebanyak 25 orang (26,9\%), presentase sampel berdasarkan daya tanggap yang tertinggi baik sebanyak 78 orang $(83,9 \%)$ sedangkan yang terendah kurang baik sebanyak 15 orang $(16,1 \%)$, presentase sampel berdasarkan jaminan yang tertinggi baik sebanyak 75 orang $(80,6 \%)$ sedangkan yang terendah kurang baik sebanyak 18 orang $(19,4 \%)$, presentase sampel berdasarkan empati yang tertinggi baik sebanyak 90 orang $(96,8 \%)$ sedangkan yang terendah kurang baik sebanyak 3 orang $(3,2 \%)$, presentase sampel berdasarkan Kepuasan yang tertinggi puas sebanyak 61 orang $(65,6 \%)$ sedangkan yang kurang puas sebanyak 32 orang $(34,4 \%)$. c. Analisis Bivariat

Tabel 3

Hubungan Antara Kualitas

Pelayanan Bukti Fisik

(Tangibles) dengan Kepuasan

Pasien BPJS di Instalasi

Rawat Jalan RSUD

Labuang Baji Makassar

83,9 Bukti Fisik Kepuasan Pasien BPJS

(Tangibles) Puas $\quad$ Kurang Jumlah ai p

\begin{tabular}{ccccccc}
\cline { 2 - 7 } 16,1 & $\mathbf{n}$ & $\mathbf{\%}$ & $\mathbf{n}$ & $\mathbf{\%}$ & $\mathbf{n}$ & $\mathbf{\%}$ \\
\cline { 2 - 7 } & 52 & 66,7 & 26 & 33,3 & 78 & 100
\end{tabular}

83,9 Kurang Baik

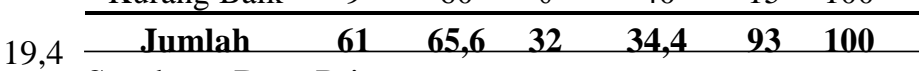

80,6 Sumber : Data Primer

Pada tabel 3 menunjukkan

3,2 bahwa dari 78 responden,

96,8 menunjukkan bahwa 52 orang $(66,7 \%)$ yang menyatakan puas

34,4 terhadap kualitas pelayanan bukti 65,6 fisik (tangibles) yang baik dan 26

100 orang $(33,3 \%)$ yang menyatakan

kurang puas, sedangkan 15 responden menunjukkan kurang puas 6 orang (40\%) terhadap kualitas pelayanan (tangibles) yang kurang baik dan 9 orang $(60 \%)$ menyatakan puas.

Hasil uji chi square diperoleh

nilai $\mathrm{p}=0,61$

$>0,05$ yang berarti tidak terdapat hubungan antara kualitas pelayanan bukti fisik (tangibles) dengan kepuasan pasien BPJS di Instalasi Rawat Jalan RSUD Labuang Baji Makassar.

\section{Tabel 4}

Hubungan Antara Kualitas

Pelayanan Kehandalan

(Reliability)dengan Kepuasan

Pasien BPJS di Instalasi

Rawat Jalan RSUD Labuang

Baji Makassar Tahun 2019

\begin{tabular}{|c|c|c|c|c|c|c|c|}
\hline \multirow{3}{*}{$\begin{array}{c}\text { Kehandalan } \\
\text { (Reliability) }\end{array}$} & \multicolumn{4}{|c|}{ Kepuasan Pasien BPJS } & \multirow{2}{*}{\multicolumn{2}{|c|}{ Jumlah }} & \multirow{2}{*}{$\begin{array}{l}\text { Nilai } \\
\mathbf{p}\end{array}$} \\
\hline & \multicolumn{2}{|c|}{ Puas } & \multicolumn{2}{|c|}{$\begin{array}{c}\text { Kurang } \\
\text { Puas }\end{array}$} & & & \\
\hline & $\mathrm{n}$ & $\%$ & $\mathrm{n}$ & $\%$ & $\mathrm{n}$ & $\%$ & \\
\hline Baik & 50 & 73,5 & 18 & 26,5 & 68 & 100 & \\
\hline Kurang Baik & 11 & 44 & 14 & 56 & 25 & 100 & $\mathbf{0 , 0 0}$ \\
\hline
\end{tabular}


$\begin{array}{llllllll}\text { Jumlah } & 61 & \mathbf{6 5 , 6} & \mathbf{3 2} & \mathbf{3 4 , 4} & \mathbf{9 3} & \mathbf{1 0 0} & \text { kurang puas, sedangkan } 15 \text { responden }\end{array}$

Sumber : Data Primer

$$
\text { Pada tabel } 4
$$

menunjukkan bahwa dari 68 responden, menunjukkan bahwa 50 orang $(73,5 \%)$ yang menyatakan puas terhadap kualitas pelayanan Kehandalan (Reliability) yang baik dan 18 orang $(26,5 \%)$ yang menyatakan kurang puas, sedangkan 25 responden menunjukkan kurang puas 14 orang $(56 \%)$ terhadap kualitas pelayanan Kehandalan (Reliability) yang kurang baik dan 11 orang $(44 \%)$ menyatakan puas.

Hasil uji chi square diperoleh nilai $\mathrm{p}=0,00<0,05$ yang berarti terdapat hubungan antara kualitas pelayanan Kehandalan (Reliability) dengan kepuasan pasien BPJS di Instalasi Rawat Jalan RSUD Labuang Baji Makassar.

Tabel 5

Hubungan Antara Kualitas

Pelayanan Daya Tanggap

(Responsiveness) dengan Kepuasan

Pasien BPJSdi Instalasi Rawat Jalan RSUD Labuang Baji Makassar Tahun 2019

\begin{tabular}{|c|c|c|c|c|c|c|c|}
\hline \multirow{3}{*}{$\begin{array}{c}\text { Daya } \\
\text { Tanggap } \\
\text { (Responsive } \\
\text { ness) }\end{array}$} & \multirow{2}{*}{\multicolumn{4}{|c|}{$\begin{array}{c}\text { Kepuasan Pasien } \\
\text { BPJS } \\
\end{array}$}} & \multirow{2}{*}{\multicolumn{2}{|c|}{ Jumlah }} & Nila(assurance) yang baik dan 19 ora \\
\hline & & & & & & & $\mathbf{i} \mathbf{p}(25,3 \%)$ yang menyatakan kurang p \\
\hline & \multicolumn{2}{|c|}{ Puas } & \multicolumn{2}{|c|}{$\begin{array}{c}\text { Kurang } \\
\text { Puas }\end{array}$} & & ian & $\begin{array}{l}18 \text { responden menunju } \\
13 \text { orang }(72.2 \%) \text { terh }\end{array}$ \\
\hline & $\mathbf{n}$ & $\%$ & $\mathbf{n}$ & $\%$ & $\mathrm{n}$ & $\%$ & \\
\hline Baik & 55 & 70,5 & $\overline{23}$ & 29,5 & & $\overline{100}$ & $u r$ \\
\hline $\begin{array}{c}\text { Kurang } \\
\text { Baik }\end{array}$ & 6 & 40 & 9 & 60 & 15 & 100 & $\begin{array}{l}\text { kurang baik } \\
\mathbf{0 , 0 2} \text { menyatakan pua }\end{array}$ \\
\hline
\end{tabular}

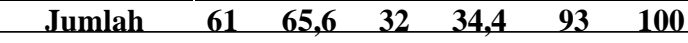

Sumber : Data Primer

$$
\text { Pada tabel } 5 \text { menunjukkan }
$$

bahwa dari 78 responden, menunjukkan bahwa 55 orang $(70,5 \%)$ yang menyatakan puas terhadap

kualitas pelayanan daya tanggap (responsiveness) yang baik dan 23 orang $(29,5 \%)$ yang menyatakan menunjukkan kurang puas 9 orang $(60 \%)$ terhadap kualitas pelayanan daya tanggap (responsiveness) yang kurang baik dan 6 orang $(40 \%)$ menyatakan puas.

Hasil uji chi square diperoleh nilai $\mathrm{p}=0,02<0,05$ yang berarti terdapat hubungan

antara kualitas pelayanan daya tanggap (responsiveness) dengan kepuasan pasien BPJS di Instalasi Rawat Jalan RSUD Labuang Baji Makassar.

Tabel 7

Hubungan Antara Kualitas Pelayanan Jaminan

(Assurance) dengan Kepuasan Pasien BPJS di

Instalasi Rawat Jalan RSUD Labuang Baji

\begin{tabular}{|c|c|c|c|c|c|c|c|}
\hline \multirow{4}{*}{$\begin{array}{c}\text { Jaminan } \\
\text { (Assurance) }\end{array}$} & \multirow{2}{*}{\multicolumn{4}{|c|}{$\begin{array}{c}\text { Kepuasan Pasien } \\
\text { BPJS }\end{array}$}} & \multirow{2}{*}{\multicolumn{2}{|c|}{ Jumlah }} & \multirow{4}{*}{$\begin{array}{l}\text { Nila } \\
\text { i p }\end{array}$} \\
\hline & & & & & & & \\
\hline & \multicolumn{2}{|c|}{ Puas } & \multicolumn{2}{|c|}{$\begin{array}{c}\text { Kurang } \\
\text { Puas }\end{array}$} & & lah & \\
\hline & n & $\%$ & $\mathbf{N}$ & $\%$ & $\mathrm{n}$ & $\%$ & \\
\hline Baik & 56 & 74,7 & 19 & 25,3 & 75 & 100 & \\
\hline $\begin{array}{c}\text { Kurang } \\
\text { Baik }\end{array}$ & 5 & 27,8 & 13 & 72,2 & 18 & 100 & 0,00 \\
\hline Jumlah & 61 & 65,6 & 32 & 34,4 & 93 & 100 & \\
\hline
\end{tabular}

Makassar Tahun 2019

Sumber : Data Primer

Pada tabel 7 menunjukkan bahwa dari 75 responden, menunjukkan bahwa 56 orang $(74,7 \%)$ yang menyatakan puas terhadap kualitas pelayanan jaminan Nila (assurance) yang baik dan 19 orang (8) kurang puas 13 orang $(72,2 \%)$ terhadap ${ }^{, 02}$ menyatakan puas.

Hasil uji chi square diperoleh nilai $\mathrm{p}=0,00$

$<0,05$ yang berarti terdapat hubungan antara kualitas pelayanan jaminan (assurance) dengan kepuasan pasien BPJS di Instalasi Rawat Jalan RSUD Labuang Baji Makassar.

Tabel 6

Hubungan Antara Kualitas Pelayanan Empati 
(Emphaty) dengan Kepuasan Pasien BPJS di

Instalasi Rawat Jalan RSUD Labuang Baji

Makassar Tahun 2019

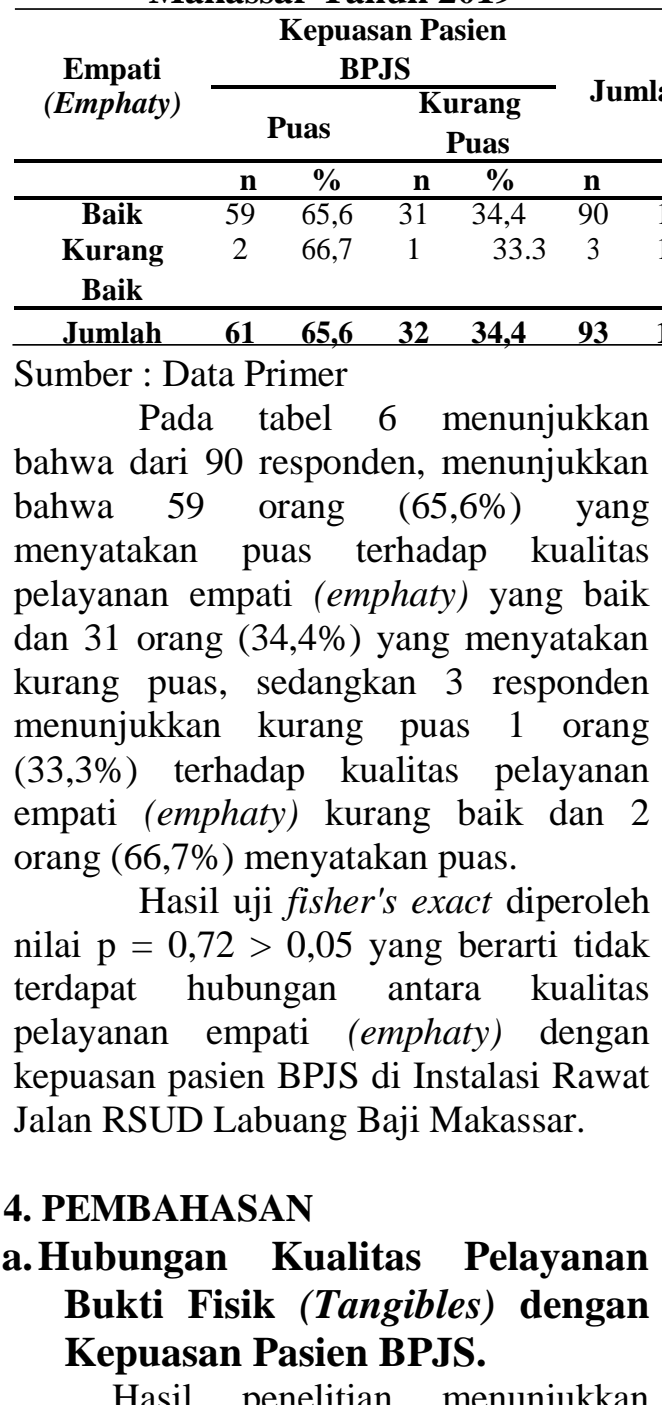

Hasil penelitian menunjukkan bahwa dari 78 responden, menunjukkan bahwa 52 orang $(66,7 \%)$ yang menyatakan puas terhadap kualitas pelayanan bukti fisik (tangibles) yang baik dan 26 orang $(33,3 \%)$ yang menyatakan kurang puas, sedangkan 15 responden menunjukkan kurang puas 6 orang (40\%) terhadap kualitas pelayanan (tangibles) yang kurang baik dan 9 orang (60\%) menyatakan puas.

Hasil uji statistic chi square diperoleh nilai $p$

$=0,61>0,05$ yang berarti tidak terdapat hubungan antara kualitas pelayanan bukti fisik (tangibles) dengan kepuasan pasien
BPJS di Instalasi Rawat Jalan RSUD Labuang Baji Makassar.

Bukti fisik (tangibles) adalah kemampuan suatu perusahaan dalam menunjukkan aksistensinya kepada pihak

Nikksternal. Penampilan kantor dan

i Raryawan, kemampuan sarana dan prasarana fisik perusahaan (termasuk fasilitas komunikasi), serta lingkungan sekitarnya adalah bukti nyata dari o, 7.2 elayanan yang diberikan oleh pembeli jasa. Penampilan pelayanan tidak hanya sebatas pada penampilan fisik bangunan yang megah tetapi juga penampilan petugas dan ketersediaan sarana dan prasarana penunjang (Lupiyoadi dalam Anung, 2015).

Hasil penelitian ini sejalan dengan penelitian yang dilakukan oleh Jelly Juliany Mentang dkk (2018), dengan judul hubungan antara kualitas jasa pelayanan kesehatan dengan kepuasan pasien di Puskesmas Taratara Kota Tomohon, dengan hasil yang menunjukkan nilai $\mathrm{p}=0,13>0,05$ yang berarti tidak ada hubungan yang bermakna antara dimensi bukti fisik (tangibles) dengan kepuasan pasien di Puskesmas Taratara Kota Tomohon.

Berbeda dengan hasil penelitian yang dilakukan Muhammad dkk (2015), dengan judul hubungan antara kualitas pelayanan kesehatan rawat jalan dengan tingkat kepuasan pasien peserta JKN di Puskesmas Siko Ternate, menyimpulkan bahwa dimensi bukti fisik (tangibles) berpengaruh terhadap tingkat kepuasan pasien peserta JKN di Puskesmas Siko Ternate.

\section{Hubungan Kualitas Pelayanan Kehandalan (Reliability) dengan Kepuasan Pasien BPJS}

Hasil penelitian menunjukkan bahwa dari 68 responden, menunjukkan bahwa 50 orang $(73,5 \%)$ yang menyatakan puas terhadap kualitas pelayanan Kehandalan (Reliability) yang baik dan 18 orang (26,5\%) yang menyatakan kurang puas, sedangkan 25 responden menunjukkan kurang puas 14 orang $(56 \%)$ terhadap kualitas pelayanan Kehandalan (Reliability) yang kurang 


\section{JURNAL DELIMA HARAPAN 2021}

baik dan 11 orang (44\%) menyatakan puas.

Hasil uji statistic chi square diperoleh nilai $\mathrm{p}$

$=0,00<0,05$ yang berarti terdapat hubungan antara kualitas pelayanan Kehandalan (Reliability) dengan kepuasan pasien BPJS di Instalasi Rawat Jalan RSUD Labuang Baji Makassar.

Hal ini menunjukkan bahwa penilaian responden terhadap kepuasan pelayanan tentang kemampuan petugas rumah sakit memberikan pelayanan dengan cepat, keberadaan dokter sesuai jadwal kerja poliklinik, pasien dilayani sesuai dengan jadwal yang telah ditetapkan, dan alur pengobatan. Masih terdapatnya kelompok pasien yang kurang puas terhadap pelayanan di rumah sakit, berarti harus ditingkatkan lagi kualitas pelayanan kehandalan (Reliability).

Kehandalan (Reliability) adalah kemampuan perusahaan untuk memberikan pelayanan sesuai dengan dijanjikan secara akurat dan terpercaya. Kinerja harus sesuai dengan harapan pelanggan yang berarti ketepatan waktu, pelayanan yang sama untuk semua pelanggan tanpa kesalahan, sikap yang simpatik dan dengan akurasi yang tinggi (Tjiptono, Chandra dan Adriana:2008).

Hasil penelitian ini sejalan dengan penelitian yang dilakukan oleh Suparta dkk (2018), dengan judul hubungan mutu pelayanan terhadap kepuasan Hasil penelitian ini sejalan dengan penelitian yang dilakukan oleh Suparta dkk (2018), dengan judul hubungan mutu pelayanan terhadap kepuasan pasien di poli umum Puskesmas Lompoe Kota Pare-pare dengan hasil yang menunjukkan nilai $\mathrm{p}=$ 0,01

$<0,05$ yang berarti terdapat hubungan yang bermakna antara dimensi kehandalan (Reliability) terhadap kepuasan pasien di poli umum Puskesmas Lompoe Kota Pare-pare.

Penelitian ini sejalan juga dengan penelitian yang dilakukan oleh Puji Pertiwi (2016), yang berjudul Hubungan kepuasan pasien pengguna BPJS terhadap kualitas pelayanan kesehatan di puskesmas Nagrak Sukabumi, terdapat hubungan yang signifikan antara kepuasan pasien terhadap dimensi kehandalan di puskesmas Nagrak Sukabumi.

\section{Hubungan Kualitas Pelayanan Daya Tanggap (Responsiveness) dengan Kepuasan Pasien \\ BPJS \\ Hasil penelitian menunjukkan} bahwa dari 78 responden, menunjukkan bahwa 55 orang $(70,5 \%)$ yang menyatakan puas terhadap kualitas pelayanan daya tanggap (responsiveness) yang baik dan 23 orang $(29,5 \%)$ yang menyatakan kurang puas, sedangkan 15 responden menunjukkan kurang puas 9 orang $(60 \%)$ terhadap kualitas pelayanan daya tanggap (responsiveness) yang kurang baik dan 6 orang (40\%) menyatakan puas.

Hasil uji chi square diperoleh nilai $p=0,02<0,05$ yang berarti terdapat hubungan antara kualitas pelayanan Daya Tanggap (Responsiveness) dengan kepuasan pasien BPJS di Instalasi Rawat Jalan RSUD Labuang Baji Makassar.

Hal ini menunjukkan bahwa penilaian responden terhadap kepuasan pelayanan kecekatan dokter dalam memberikan pertolongan, kejelasan informasi pengobatan, dan kejelasan mengenai keluhan pasien. Masih terdapatnya kelompok pasien yang kurang puas terhadap pelayanan di rumah sakit, berarti harus ditingkatkan lagi kualitas pelayanan daya tanggap (Rsponsiveness).

Responsiveness adalah tanggap memberikan pelayanan yang cepat atau responsif serta diiringi dengan cara penyampaian yang jelas dan mudah dimengerti (A. Pasuraman, 2010).

Hasil penelitian ini sejalan dengan penelitian yang dilakukan oleh Saputra Adisurya dan Ariyani Nurlita (2018), dengan judul hubungan pelayanan mutu kesehatan dengan kepuasan pasien rawat jalan pengguna kartu BPJS di Rumah Sakit Daerah Idaman Kota Banjarbaru dengan hasil yang menunjukkan nilai $\mathrm{p}=$ $0,00<0,05$ yang berarti terdapat hubungan yang bermakna antara dimensi 
daya tanggap (responsiveness) terhadap kepuasan pasien rawat jalan pengguna kartu BPJS di Rumah Sakit Daerah Idaman Kota Banjarbaru.

Penelitian ini sejalan juga dengan penelitian yang dilakukan oleh Suparta dkk (2018), yang berjudul hubungan mutu pelayanan terhadap kepuasan pasien di poli umum puskesmas Lompoe kota Pare-pare, dengan hasil yang menunjukkan nilai $\mathrm{p}=0,00<0,05$ yang berarti terdapat hubungan yang bermakna antara dimensi daya tanggap (Responsiveness) dengan kepuasan pasien di puskesmas Lompoe kota Parepare.

\section{Hubungan Kualitas Pelayanan Jaminan (Assurance) dengan Kepuasan Pasien BPJS}

Hasil penelitian menunjukkan bahwa dari 75 responden, menunjukkan bahwa 56 orang $(74,7 \%)$ yang menyatakan puas terhadap kualitas pelayanan jaminan (assurance) yang baik dan 19 orang $(25,3 \%)$ yang menyatakan kurang puas, sedangkan 18 responden menunjukkan kurang puas 13 orang $(72,2 \%)$ terhadap kualitas pelayanan jaminan (assurance) kurang baik dan 5 orang $(27,8 \%)$ menyatakan puas.

Hasil uji chi square diperoleh nilai $\mathrm{p}=0,00<0,05$ yang berarti terdapat hubungan antara kualitas pelayanan Jaminan (Assurance) dengan kepuasan pasien BPJS di Instalasi Rawat Jalan RSUD Labuang Baji Makassar.

Hal ini menunjukkan bahwa penilaian responden terhadap kepuasan pelayanan tentang penjelasan dokter mengenai penyakit pasien, cara perawat dalam memberikan tindakan, tenaga medis bersifat cekatan serta menghargai pasien dan kesediaan obat-obatan yang dibutuhkan oleh pasien. Masih terdapatnya kelompok pasien yang kurang puas terhadap pelayanan di rumah sakit, berarti harus

ditingkatkan lagi kualitas pelayanan jaminan (assurance).

Jaminan (Assurance) adalah jaminan dan kepastian yang diperoleh dari sikap sopan santun karyawan, komunikasi yang baik, dan pengetahuan yang dimiliki, sehingga mampu menumbuhkan rasa percaya pelanggan (A. Pasuraman 2010).

Hasil penelitian ini sejalan dengan penelitian yang dilakukan oleh Arini Curri Firdaus (2018), dengan judul hubungan mutu pelayanan kesehatan dengan kepuasan pasien BPJS rawat jalan poli penyakit dalam di RSUD Dr.Soeratmo Gemolong dengan hasil yang menunjukkan nilai $\mathrm{p}=0,00<0,05$ yang berarti terdapat hubungan yang bermakna antara dimensi Jaminan (Assurance) dengan kepuasan pasien BPJS rawat jalan poli penyakit dalam di RSUD Dr.Soeratmo Gemolong.

Penelitian ini sejalan juga dengan penelitian yang dilakukan oleh Mutiara Hanna dkk (2018), dengan judul hubungan mutu pelayanan dengan kepuasan pasien peserta BPJS di RSUD dr. H. Abdul Moeloek, dengan hasil yang menunjukkan nila $\mathrm{p}=0,00<0,05$ yang berarti terdapat hubungan yang bermakna antara dimensi Jaminan (Assurance) dengan kepuasan pasien

\section{Hubungan Kualitas Pelayanan dengan Empati (Emphaty) Kepuasan Pasien BPJS}

Hasil penelitian menunjukkan bahwa dari 90 responden, menunjukkan bahwa 59 orang $(65,6 \%)$ yang menyatakan puas terhadap kualitas pelayanan empati (emphaty) yang baik dan 31 orang $(34,4 \%)$ yang menyatakan kurang puas, sedangkan 3 responden menunjukkan kurang puas 1 orang $(33,3 \%)$ terhadap kualitas pelayanan empati (emphaty) kurang baik dan 2 orang $(66,7 \%)$ menyatakan puas.

Hasil uji statistic chi square

diperoleh nilai $\mathrm{p}$

$=0,72>0,05$ yang berarti tidak terdapat hubungan antara kualitas pelayanan Empati (Emphaty) dengan kepuasan pasien BPJS di Instalasi Rawat Jalan RSUD Labuang Baji Makassar.

Hampir semua responden merasa puas terhadap pelayanan di rumah sakit dikarenakan responden merasa dokter memberikan waktu pelayanan yang cukup pada pasien, perawat mendengar secara seksama setiap keluhan pasien, 
dan petugas kesehatan melayani tanpa membedakan status social pasien.

Empati (empathy) Maknanya memberikan perhatian yang tulus dan bersifat individual atau pribadi yang diberikan kepada para pelanggan dengan berupaya memahami keinginan konsumen.

Dimana suatu perusahaan diharapkan memilki pengertian dan pengethauan tentang pelanggan, memahami kebuthuhan pelanggan secara spesifik, serta memilki waktu pengoperasian yang nyaman bagi pelanggan (Tjiptono, Chandra dan Adriana 2008).

Hasil penelitian ini sejalan dengan penelitian yang dilakukan oleh Jelly Juliany Mentang dkk (2018), dengan judul hubungan antara kualitas jasa pelayanan kesehatan dengan kepuasan pasien di Puskesmas Taratara Kota Tomohon, dengan hasil yang menunjukkan nilai $\mathrm{p}=0,13<0,05$ yang berarti tidak terdapat hubungan yang bermakna antara dimensi empati (Emphaty) dengan kepuasan pasien di Puskesmas Taratara Kota Tomohon.

Penelitian ini tidak sejalan dengan penelitian yang dilakukan oleh Arini Curri Firdaus (2018), dengan judul hubungan mutu pelayanan kesehatan dengan kepuasan pasien BPJS rawat jalan poli penyakit dalam di RSUD Dr.Soeratmo Gemolong dengan hasil yang menunjukkan nilai $\mathrm{p}=0,00<0,05$ yang berarti terdapat hubungan yang bermakna antara dimensi empati (Emphaty) dengan kepuasan pasien BPJS rawat jalan poli penyakit dalam di RSUD Dr.Soeratmo Gemolong.

\section{Kesimpulan}

Berdasarkan hasil penelitian ini mengenai Hubungan Kualitas Pelayanan dengan Kepuasan Pasien BPJS di Instalasi Rawat Jalan RSUD Labuang Baji Makassar dapat ditarik kesimpulan sebagai berikut:

1. Tidak ada hubungan antara kualitas pelayanan bukti fisik (Tangibles) dengan kepuasan pasien BPJS di
Instalasi Rawat Jalan RSUD Labuang Baji Makassar.

2. Ada hubungan antara kualitas pelayanan kehandalan (reliability) dengan kepuasan pasien BPJS di Instalasi Rawat Jalan RSUD Labuang Baji Makassar.

3. Ada hubungan antara kualitas pelayanan daya tanggap (responsiveness) dengan kepuasan pasien BPJS di Instalasi Rawat Jalan RSUD Labuang Baji Makassar.

4. Ada hubungan antara kualitas pelayanan jaminan (assurance) dengan kepuasan pasien BPJS di Instalasi Rawat Jalan RSUD Labuang Baji Makassar.

5. Tidak ada hubungan antara kualitas pelayanan empati (emphaty) dengan kepuasan pasien BPJS di Instalasi Rawat Jalan RSUD Labuang Baji Makassar.

\section{Saran}

Dalam rangka meningkatkan kepuasan pasien BPJS di Instalasi Rawat Jalan RSUD Labuang Baji, perlu meningkatkan kualitas pelayanan, maka disarankan:

1. Kepada RSUD Labuang Baji

Makassar perlu

meningkatkan lagi kualitas pelayanan (kehandalan, daya tanggap, dan jaminan) dalam melaksanakan pelayanan kesehatan sehingga dapat meningkatkan kepuasan pasien BPJS di Instalasi Rawat Jalan.

2. Kepada peneliti selanjutnya, perlu dilakukan penelitian lebih lanjut tentang hubungan antara kualitas pelayanan kehandalan, daya tanggap, dan jaminan dengan kepuasan pasien BPJS di instalasi Rawat jalan rumah sakit Labuang Baji Makassar.

\section{Daftar Pustaka}

Anung,Evyyanti. 2015. Hubungan Kualitas Pelayanan Perawat dengan Tingkat Kepuasan Pasien Rawat Inap di RSUD Kalabahi Kabupaten Alor. Skripsi STIK Makassr Program Study Kesehatan Masyarakat. 
Aprilyani, A, dkk. 2016. Hubungan Mutu Pelayanan Kesehatan dengan Kepuasan Pasien Rawat Jalan di Puskesmas Antang Kota Makassar. Jurnal Kesehatan Masyarakat.

Burhanuddin. 2015. Hubungan Mutu Pelayanan Kesehatan dengan Kepuasan Pasien RSUD Syekh Yusuf Gowa. Jurnal MKMI 12(1): 42-46.

Dewi, M. 2016. Pengaruh Kualitas Pelayanan Terhadap Kepuasan Pasien Pengguna BPJS pada Rumah Sakit Rehabilitas Medik Kabupaten Aceh Timur. Jurnal Manajemen dan Keuangan 5(2): 537-542.

Fattah, A. 2016. Hubungan Kualitas Pelayanan Kesehatan Terhadap Loyalitas Pasien di Rawat Inap Rumah Sakit Ibu dan Anak Siti Khadijah Makassar. Skipsi UIN Alauddin Program Studi Kedokteran dan Ilmu Kesehatan.

Firdaus, A. 2018. Hubungan Mutu Pelayanan Kesehatan Dengan Kepuasan Pasien BPJS di Rawat Jalan Poli Penyakit Dalam Di RSUD Dr. SoeratnoGemolong. Jurnal Kesehatan Masyarakat.

Ilahi, P. 2016. Hubungan Kepuasan Pasien Pengguna BPJS terhadap Kualitas Pelayanan Kesehatan di Puskesmas Negrak Sukabumi. Skripsi UIN Syarif Hidayatullah Program Studi Keperawatan.

Kementrian Kesehatan Tahun 2013. Sosialisasi Jaminan

Kesehatan Nasional

Sosial.

Dalam Sistem Jaminan

Mentang, J., dkk. 2018. Hubungan Antara Kualitas Jasa Pelayanan Kesehatan dengan Kepuasan Pasien di Puskesmas Taratara Kota Tomohon. Jurnal Kesehatan Masyarakat.

Muhammad, Aminuddin, dan Umboh, Tucunan. 2015. Hubungan Antara Kualitas Pelayanan Kesehatan Rawat Jalan Dengan Tingkat Kepuasan Pasien Peserta Jaminan Kesehatan Nasional di Puskesmas Siko Ternate. Jurnal Kesehatan Masyarakat.

Mukhtar, M. 2017 Pengaruh Kualitas Pelayanan Jasa Kesehatan BPJS di
Era Jaminan Kesehatan Nasional Terhadap Kepuasan Pasien di Rumah Sakit Daya Makassar. Skripsi UNHAS Program Studi Ekonomi dan Bisnis.

Peraturan Menteri Pendayagunaan Aparatur Negara dan Reformasi Birokrasi Republik Indonesia Nomor 14 Tahun 2017. Pedoman Penyusunan Survei Kepuasan Masyarakat Unit Penyelenggaraan Pelayanan Publik.

Puji Pertiwi. (2016). Hubungan

Kepuasan Pasien Pengguna BPJS Terhadap Kualitas

Pelayanan Kesehatan Di Puskesmas Nagrak Sukabumi.

Saputra, A., dan Ariani, Nurlita. 2018. Hubungan Mutu Pelayanan Kesehatan dengan Kepuasan Pasien Rawat Jalan Pengguna Kartu BPJS di Rumah Sakit Daerah Idaman Kota Banjarbaru. Jurnal Keperawatan Borneo.

Sulistyo, P. 2016. Hubungan Kualitas Pelayanan Kesehatan dengan Kepuasan Pasien BPJS Di Puskesmas Delanggu Kabupaten Klaten. Skripsi Stikes Kusuma Husada Program Studi Keperawatan.

Suparta, H., dan Kamsir, A. 2018. Hubungan Mutu Pelayanan Terhadap Kepuasan Pasien Di Poli Umum Puskesmas Lompoe Kota Pare-par. Jurnal Ilmiah Kesehatan Pencerah.

Tjiptono, Chandra dan Adriana. 2008. Dimensi Kualitas Pelayanan.

https://etalasepustaka.blogspot.com/2 016/05/pengertian-dimensi-kualitaspelayanan-menurut-para-ahli.html.

16 September 2019 (23.46).

Undang-Undang Republik Indonesia

Nomor 24 Tahun

2011. Badan

Penyelenggaraan Jaminan Sosial.

Undang-Undang Republik Indonesia Nomor 40 Tahun 2004. Sistem Jaminan Sosial

Nasional.

Wahyuliani, Nopia. 2016. Hubungan Mutu 
Pelayanan Rumah Sakit dengan

Kepuasan Pasien BPJS Kesehatan di Instalasi Rawat Inap Kelas III

Rumah Sakit Umum Penembahan

Senopati

Bantu

WHO.2015. Hospital.

http://www.who.int/topics/hospitals/e n/. 15 Mei 2019 (14.37).

Yusuf, Israwati. 2017.Hubungan Mutu Pelayanan dengan Kepuasan Pasien Rawat Inap di Rumah Sakit Haji Andi Sultan DG Radja Kabupaten Bulukumba. Skripsi Stikes Program Studi Kesehatan Msyarakat. 